San Jose State University

SJSU ScholarWorks

Master's Theses

Master's Theses and Graduate Research

1989

\title{
Reproducibility and application of perceived exertion ventilatory threshold for trained runners
}

Gunnar Pall Joakimsson

San Jose State University

Follow this and additional works at: https://scholarworks.sjsu.edu/etd_theses

\section{Recommended Citation}

Joakimsson, Gunnar Pall, "Reproducibility and application of perceived exertion ventilatory threshold for trained runners" (1989). Master's Theses. 3081.

DOI: https://doi.org/10.31979/etd.33gt-93f3

https://scholarworks.sjsu.edu/etd_theses/3081

This Thesis is brought to you for free and open access by the Master's Theses and Graduate Research at SJSU ScholarWorks. It has been accepted for inclusion in Master's Theses by an authorized administrator of SJSU ScholarWorks. For more information, please contact scholarworks@sjsu.edu. 


\section{INFORMATION TO USERS}

The most advanced technology has been used to photograph and reproduce this manuscript from the microfilm master. UMI films the text directly from the original or copy submitted. Thus, some thesis and dissertation copies are in typewriter face, while others may be from any type of computer printer.

The qusility of this reproduction is dependent upon the quality of the copy submitted. Broken or indistinct print, colored or poor quality illustrations and photographs, print bleedthrough, substandard margins, and improper alignment can adversely affect reproduction.

In the unlikely event that the author did not send UMI a complete manuscript and there are missing pages, these will be noted. Also, if unauthorized copyright material had to be removed, a note will indicate the deletion.

Oversize materials (e.g., maps, drawings, charts) are reproduced by sectioning the original, beginning at the upper left-hand corner and continuing from left to right in equal sections with small overlaps. Each original is also photographed in one exposure ano is included in reduced form at the back of the book. These are also available as one exposure on a standard $35 \mathrm{~mm}$ slide or as a 17" $\times 23^{\prime \prime}$ black and white photographic print for an additional charge.

Photographs included in the original manuscript have been reproduced xerographically in this copy. Higher quality $6^{\prime \prime} \times 9^{\prime \prime}$ black and white photographic prints are available for any photographs or illustrations appearing in this copy for an additional charge. Contact UMI directly to order.

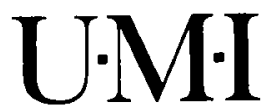


5

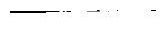


Order Number 1937815

Reproducibility and application of perceived exertion ventilatory threshold for trained runners

\author{
Joakimsson, Gunnar Pall, M.A.
}

San Jose State University, 1989 
$-$ 


\title{
REPRODUCIBILITY AND APPLICATION OF PERCEIVED EXERTION VENTILATORY THRESHOLD FOR TRAINED RUNNERS
}

\author{
A Thesis \\ Presented to \\ The Faculty of the Department of Human Performance \\ San Jose State University
}

\author{
In Partial Fulfillment \\ of the Requirements for the Degree \\ Masters of Arts
}

By

Gunnar Pall Joakimsson

May, 1989 
APPROVED FOR THE DEPARTMENT OF HUMAN PERFORMANCE

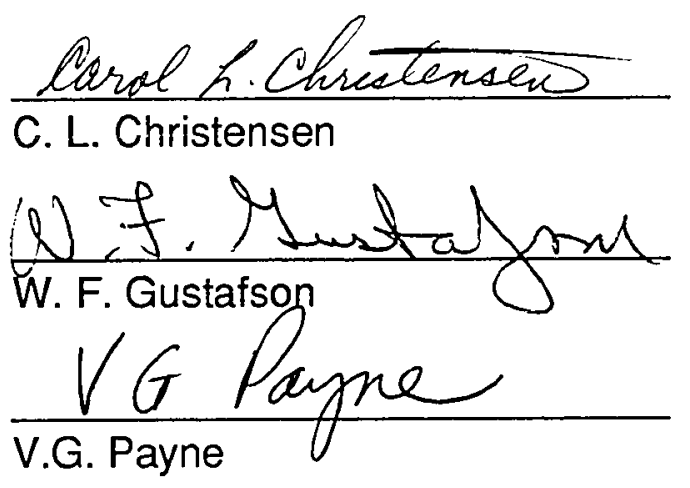

APPROVED FOR THE UNIVERSITY In. Lou Sturoudowati 


\section{Acknowledgement}

I want to use this opportunity to express my gratitude to my thesis chairperson, Dr. Carol L. Christensen, for her guidance and motivation during all my time at SJSU. I would also like to express my appreciation to the two other members of my thesis committee, Dr. V. Gregory Payne, and Dr. William F. Gustafson. I am forever thankful for their critical analysis and support during the writing of my thesis.

I also want to thank all the others who assisted me, especially my fellow graduate students Daniel Brown and Kathy Jablonsky, for all the time they volunteered to help in the laboratory.

Last but not least, I want to thank my subjects. It is extremely important to have subjects as enthusiastic and cooperative as the runners who volunteered for this study. 


\section{Abstract}

The purpose of this study was to examine the ability to reproduce ratings of perceived exertion (RPE) at ventilatory threshold. Fifteen well trained middle and long distance male runners (mean VO2max 65.7 $\mathrm{ml} / \mathrm{kg} / \mathrm{min}$ ), aged 18 to 28 , were tested on the treadmill on three different occasions. Maximal oxygen uptake (VO2max) and ventilatory threshold (VT) were determined in a graded exercise test. T'ie workload corresponding to ventilatory threshold in the maximal test was repeated in one incremental submaximal test and one interval submaximal test. Subjects indicated their RPE during the last 10 seconds of each workload using the 15-point Borg scale in all tests. The mean values for RPE were $13.8+/-2.1,13.0+/-2.8$, and $11.2+/-2.0$ for the three tests. A one way ANOVA revealed no significant difference between RPE or VंO2 at VT for the three tests at the 0.01 level of significance. The results of this study indicate that trained middle and long distance runners can reproduce RPE at VT for identical workloads and nearly identical oxygen consumptions. Ratings of perceived exertion can be used to regulate training intensity at VT. At VT the intensity was rated as "somewhat hard" to "hard" on the Borg scale. 


\section{Table of contents}

Approval page

Acknowledgement

iii

Abstract

iv

Table of contents

V

List of tables

vii

Chapter 1

Introduction

1

Statement of the problem 3

Hypothesis 3

Delimitations 3

Limitations $\quad 4$

Significance of the problem 4

Definitions 5

Chapter 2

$\begin{array}{ll}\text { Review of literature } & 7\end{array}$

Maximal oxygen uptake and its fractional use during exercise $\quad 8$

Anaerobic threshold and ventilatory threshold 10

$\begin{array}{ll}\text { Ratings of perceived exertion } & 13\end{array}$ 
Chapter 3

$\begin{array}{ll}\text { Research design } & 17\end{array}$

$\begin{array}{ll}\text { Subjects } & 17\end{array}$

$\begin{array}{ll}\text { Testing procedures } & 18\end{array}$

Measurement of physiological variables 20

Data analysis $\quad 21$

Chapter 4

Results and discussion 22

Chapter 5

Summary 31

Conclusion 32

Recommendation 33

References $\quad 34$

Appendices

Appendix A. Informed consent 43

Appendix B. Questionnaire 47

Appendix C. Borg's RPE scale 50

Appendix D. Directions for use of Borg's RPE scale 52

Appendix E. Individual data at maximal exercise and for \% body fat and weight $\quad 55$

Appendix F. Individual data for physiological variables at ventilatory threshold $\quad 58$

$\begin{array}{lll}\text { Appendix G. Publication manuscript } & 61\end{array}$ 


\section{List of tables}

Table 1. Physical characteristics of subjects

Table 2. Training characteristics 23

Table 3. Physiological variables at maximal exercise

Table 4. Physiological variables at ventilatory threshold (VT) during three treadmill tests

Table 5. Analysis of variances between ratings of perceived exertion (RPE), oxygen consumption (VOO2), and heart rate (HR) at ventilatory threshold (VT) during three treadmill tests 


\section{Chapter 1}

Introduction

The effectiveness of a training program depends upon its capability to bring forth the required physiological adaptations. Training should be event-specific since energy requirements depend on the intensity and duration of exercise (Fox \& Mathews, 1981). For endurance events which rely on aerobic energy production, the abilty to consume oxygen and utilize energy is fundamental. Researchers have shown that maximal oxygen consumption (VัO2max), or maximal aerobic power, miay increase with training and that $\dot{V} O 2 m a x$ is highest in endurance athletes (Fox et al., 1973; Saltin \& Åstrand, 1967).

However, performance can be improved with no improvement in VO2max (Daniels, Yarbrough \& Foster, 1978), and the large variation in performance between runners of equal VO2max indicates that factors other than VंO2max are of importance for performance (Sjodin \& Svedenhag, 1985). One of these factors is the anaerobic threshold (AT). Anaerobic threshold refers to the oxygen consumption (VंO2) beyond which metabolic acidosis is experienced and is therefore representative of the level at which submaximal work can be performed for a prolonged time. 
Anaerobic threshold is often thought to be a better evaluation of submaximal fitness than VO2max, and has a high correlation with endurance performance (Costill, Fink \& Pollock, 1976; Tanaka et al.,1983; Weltman, Katch, Sady \& Freedson, 1978).

In endurance events athletes can work at different percentages of their VO2max without having an accelerated lactic acid production and accompanying fatigue effects. Monitoring ventilatory response to exercise makes possible the detection the onset of metabolic acidosis as described by Sady, Katch, Freedson, and Weltman (1980).

The onset of metabolic acidosis (MA), as estimated from gas exchange variables, is thought to be near the level where non-oxidative [sic] metabolism begins to play a more predominant role in energy production. It has been shown that near this level the oxygen demand for the exercise is greater than the oxygen supply necessitating anaerobic production of ATP. In this case the lactic acid production increases resulting in non-metabolic [sic] production of carbon dioxide which serves as an immediate ventilatory stimulus. (p.41)

Intensity of training is positively related to the gain in vo2max (Davies \& Knibbs, 1971; Fox et al., 1973). High intensity training has been found to increase AT, both as an absolute value and as a percentage of VंO2max (Davis, Frank, Whipp \& Wasserman, 1979; Sady et al., 1980). In devising training programs, physiologists and coaches often recommend training intensities equal to or above the individual's AT to increase the aerobic power and the ability to work at a high percentage of 
the VO2max (Burke \& Franks, 1975; Sady, et al., 1980). Since the training intensity is important, reliable and accessible methods for evaluating training intensity are necessary. Heart rate measurement is one such technique, but using relative percent of maximal heart rate can fail to stress individuals equally in terms of energy utilization (Katch, Weltman, Sady \& Freedson, 1978). Ratings of perceived exertion (RPE) have been used successfully for exercise prescription, and should be considered as an alternate method (Burke \& Collins, 1984; Smutok, Skrinar \& Pandolf,1980).

\section{Statement of the Problem}

In this study, VT (anaerobic threshold measured as ventilatory threshold, or breaking point) and RPE were examined to determine the ability of subjects to reproduce RPE at VT with the purpose of evaluating the feasibility of trained runners using RPE to monitor exercise intensity.

Hypothesis:

There would be no significant difference between the means for the RPE at VT in three test protocols.

Delimitations

The subjects were male distance runners who met the defined 
standards required by the purpose of the study. All subjects were characterized by high aerobic power according to cardiorespiratory fitness standards given by the American College of Sports Medicine (1980). Of the physiological parameters that can be utilized to determine anaerobic or ventilatory threshold, only minute ventilation and oxygen consumption were used in this study.

\section{Limitations and Assumptions}

All subjects were assumed to be naive concerning the specific mechanics of RPE. There was no control over diet, sleep, or mood. The subject's use of the RPE scale was assumed to be the same each time. Exercise testing and ratings of perceived exertion were done only in a laboratory setting. Intensity was monitored by means of speed of treadmill, with the assumption that at a given treadmill speed the corresponding oxygen consumption would be unchanged between tests. The motivational level of the subjects at the time of testing was assumed to be at maximum.

\section{Significance of the Problem}

The evidence that VO2max and VT can be improved by training at the approximate intensity of the individual's VT emphasizes the importance of the measurement of VT to determine if trained runners can subjectively rate the exercise intensity representing VT. Ventilatory 
threshold has been measured at approximately $75 \%$ of $\dot{V} O 2 \max$ for trained runners, a value similar to the fractional vo2max use in marathon running (Costill \& Fox,1969; Maugham \& Leiper, 1983).

To monitor the training intensity, the individual can measure running pace (e.g., min per km or mile) or evaluate the physiological reactions to exercise, such as heart rate or oxygen consumption. Ratings of perceived exertion are an alternate method to evaluate the intensity of exercise. This method considers the overall stress of exercise, and therefore diminishes the danger of overtraining which is often experienced from following training schedules too strictly (Costill, 1986). Results from this study were expected to contribute to a better understanding of the subjective ratings of exercise intensity as a tool for monitoring training for distance runners.

\section{Definitions}

Maximal oxygen consumption (ن்2max). The maximal rate at which oxygen can be consumed per minute, the power of the aerobic system. In this study $\dot{\mathrm{V} O 2 m a x}$ was represented by a plateau in $\mathrm{V} O 2$, respiratory exchange ratio (RER) value of greater than one, and heart rate (HR) close to the individual's predicted maximum heart rate (Fox \& Mathews, 1981).

Anaerobic threshold (AT). The level of work or oxygen consumption at which metabolic acidosis and the associated changes in gas exchange occur (Wasserman, Whipp, Koyal \& Beaver, 1973).

Ventilatory threshold (VT). The level of work at which minute 
ventilation changes from a linear to a nonlinear increase in incremental tests !Orr, Green, Hughson \& Bennett, 1982).

Distance runners. For the purpose of this study distance runners were defined as runners who competed at distances of 1500 meters or longer and/or whose training involved runs of 10 miles or longer.

Batings of perceived exertion (RPE). The feeling of overall effects of exertion as subjectively rated by the subjects. The 15-point Borg rating scale (ranging from 6 to 20) was used for the ratings of perceived exertion (Borg, 1973).

Maximal oxygen consumption is important in all endurance events, but anaerobic threshold may be of no less importance for performance. To improve maximal oxygen consumption and anaerobic threshold it is necessary to monitor the training intensity. One method to consider for evaluating the intensity of exercise is ratings of perceived exertion. 


\section{Chapter 2}

\section{Review of Literature}

The effects of training on maximal oxygen consumption (ن்2max), fractional use of $\dot{\mathrm{O} O 2 m a x}$ during exercise, anaerobic threshold (AT) and ventilatory threshold (VT), ratings of perceived exertion (RPE), and how RPE can be used to prescribe training intensity will be discussed in this review.

The relative contribution of the aerobic and the anaerobic system to energy production during exercise is dependent upon the type of exercise. The aerobic system is predominant during rest and light exercise. As intensity is increased, the anaerobic system will be called upon when the aerobic system cannot supply all the energy needed. When anaerobic glycolysis is accelerated, it is accompanied by accumulation of blood lactate and increased minute ventilation. The contribution of the aerobic system is therefore higher in the longer and less intensive events, and the anaerobic energy sources contribute more to the shorter and more intensive events. Marathon running lasting $2 \mathrm{hrs}$ and $15 \mathrm{~min}$ is considered to be over $95 \%$ aerobic, while 800 -meter running of $1 \mathrm{~min} 45 \mathrm{sec}$ is considered to be only $35 \%$ aerobic, and 1,500-meter or 1 -mile runs being the running events closest to being evenly aerobic and anaerobic (Fox, \& 
Mathews, 1981). Training has to be event specific for optimal training effects. To accomplish this, training intensity has to be monitored.

\section{Maximal Oxygen Uptake and its Fractional Use During Exercise}

Training of the aerobic system results in increased VO2max, but there seems to be a genetic limitation to the possible improvement in maximal aerobic power. Klissouras (1971) concluded from his experiment on heritability of adaptive variation that variability in maximal aerobic power is $93.4 \%$ genetically determined. The VOOmax value will reach its peak value within ranges of six months to years of intensive training (Wilmore, 1977). Increasing vंO2max toward the individual's genetic potential is vital for optimal performance in endurance events. Runners with high VंO2max are able to delay the onset of metabolic acidosis and in that way improve performance (Weltman \& Katch, 1979).

Endurance athletes can improve their performance although vंO2max has reached plateau, and improved performance from one decade to another is more dependent on factors other than increased VO2max. Saltin and Åstrand (1967) suggest better running technique, ability to work closer to the maximum, differences in anaerobic power, and better track equipment as explanations for better performance for runners today who have no higher $\dot{\mathrm{V}} 2 \mathrm{max}$ than runners some decades ago.

The ability to work at a high percentage of $\dot{\mathrm{V}} 2 \mathrm{max}$ has been found to correlate highly with performance. LaFontaine, Londeref, and Spath (1981) found maximal steady state exercise highly correlated $(r=.90)$ 
with performance in distances from $3.22 \mathrm{~km}$ to $20 \mathrm{~km}$. Unexpected was a significant, although lower $(r=.80)$, correlation between maximai steady state and performance in $402.3 \mathrm{~m}$ (440 yards). In a study by Maugham and Leiper (1983) the fraction of $\dot{V} O 2$ max which was sustained throughout the long distance race was significantly correlated with performance for both female $(N=10)$ and male $(N=18)$ marathon runners.

How training affects the threshold for onset of metabolic acidosis has not been fully explained. Muscle respiratory capacity is thought to be of primary importance in determining the work rate at which blood lactate accumulation begins, and has been found to be significantly related to oxygen consumption (V்2), absolute lactate threshold, and the percent of type I fibers (Ivy, Withers, Van Handel, Elger \& Costili, 1980).

The higher the respiratory capacity, the lower the steady state level of adenosine diphosphate (ADP), adenosine monophosphate (AMP) and inorganic phosphate (Pi), and the higher the level of adenosine triphosphate (ATP). Glycolysis and glycogenolysis should therefore occur at a slower rate at a given submaximal work level (Holloszy, 1973). The oxidation of fat is increased with endurance training, resulting in sparing of glycogen and delaying the onset of metabolic acidosis. This is experienced in decreased respiratory exchange ratio (RER) values after training. Karlsson, Nordsjo \& Saltin (1973) found mean RER values decreased from 0.93 to 0.89 at the same workload after two months of training.

The physiological adaptation resulting from exercise depends on the 
intensity level of the exercise. Burke and Franks (1975) concluded from their experiment on the effects of different training intensities on increased VO2max that a minimum of $75 \%$ maximal heart rate (HRmax) was necessary to elicit significant changes in VO2max. Sady et al. (1980) found improved VO2max after eight weeks of training for two groups, one working at $40 \% \dot{V} O 2 m a x$ and the other working at $80 \%$ VO2max. An increased threshold for onset of metabolic acidosis was found only for the group working at the higher intensity. In the discussion of training for improved performance the focus of attention is on the maximal fractional use of $\mathrm{VO}$ max or the maximal steady state that can be sustained for a prolonged time.

\section{Anaerobic Threshold and Ventilatory Threshold}

Exercising at higher intensities than those which can be sustained for a prolonged time results in complex physiological reactions that are not fully understood. Increased blood lactate levels and increased minute ventilation (VE) are noticed with increased work intensity.

In 1964, Wasserman and Mcliroy introduced the term "anaerobic threshold" and, in 1973, Wasserman et al. described noninvasive measurements to determine anaerobic threshold that have since been widely used. They defined anaerobic threshold as "the level of work or $\mathrm{O} 2$ consumption just below at which [sic] metabolic acidosis and the associated changes in gas exchange occur" (Wasserman et al., 1973, p. 236). The hypothesis of these researchers was that local muscle hypoxia 
was responsible for the increased blood lactate levels and concomitant rise in minute ventilation. Ventilation control mechanisms attempt to maintain homeostasis of arterial PCO2 and $\mathrm{H}+$ and excess $\mathrm{CO} 2$, with increased $\mathrm{H}+$ from buffering of lactic acid causing the increase in ventilation. This hypothesis has been supported by two other studies (Caiozzo et al., 1982; Powers, Dodd \& Garner, 1984). Some studies have failed to find a correlation between lactate and ventilatory threshold and the hypothesis that anaerobic threshold is related to the onset of muscle anaerobic metabolism caused by hypoxia has been questioned. In a study by Hughes, Turner, and Brooks (1982), alterations in pedaling frequency and muscle glycogen content produced a significant divergence of lactate and ventilatory threshold. Ventilatory threshold has been observed in patients with McArdle's disease but these patients lack the enzyme phosphyrolase and therefore produce no lactic acid (Hagberg et al., 1982). Graham (1984) pointed out that blood lactate reflects the balance of lactate entry and lactate clearance but not muscle lactate production.

Weltman and Katch (1979) discussed the findings of studies which suggest that increased blood lactate levels may not be due to muscle hypoxia and concluded:

In light of the above, it seems more appropriate to refer to the "anaerobic threshold" in terms of the onset of metabolic acidosis rather than necessarily signaling the onset of increased anaerobic metabolism caused by muscle hypoxia. This in no way detracts from the usefulness of the anaerobic threshold concept for understanding exercise energetics nor [sic] its clinical importance. 
(p. 139)

Skinner and McLellan (1980) and Kinderman, Simon, and Keul (1979) suggested another definition of the threshold levels in the transition from aerobic to anaerobic energy sources. Their conclusion was that the threshold generally named AT is more related to imbalance between pyruvate production and pyruvate oxidation and less to anaerobiosis and suggested that this threshold level (blood lactate approximately 2 $\mathrm{mmol} / \mathrm{l}$ ) be named aerobic threshold. A later threshold point (blood lactate approximately $4 \mathrm{mmol} / \mathrm{l}$ ) with an exponential increase in blood lactate and increasing fast twitch fiber recruitment is in their opinion more related to anaerobiosis and should therefore be named anaerobic threshold.

Some researchers have used the arbitrary value of $4 \mathrm{mmol} / \mathrm{l}$ of blood lactate to detect the anaerobic threshold but in some instances endurance athletes seem to be able to exercise for prolonged periods of time with blood lactate levels over $4 \mathrm{mmol} / \mathrm{l}$ (Rusko \& Rahkila, 1982). The preference of VT over blood lactate variables as a training criterion has been addressed by Brooks and Fahey (1984): "determination of the ventilatory inflection point (Tvent) is probably a more appropriate training criterion than is the determination of a blood lactate inflection point (Tlact) or a blood lactate level of 4 mM" (p.437).

According to Hughson (1984) the ventilatory threshold may be a very sensitive indicator of interventions such as training and should be considered in fitness tests whether or not a blood lactate response has been shown to coincide with the point. When looking at performance in 
$10 \mathrm{~km}$ race for trained male runners Powers, Dodd, Deason, Byrd, and McKnight (1983) concluded that VT can account for a large portion of the variance in performance for runners with similar VंO2max.

There is controversy over the terminology used for anaerobic threshold and reiated concepts. Instead of talking about anaerobic threshold the term ventilatory threshold has been used to describe the threshold phenomenon with non-invasive tests measuring changes in minute ventilation during incremental testing. (Hughson, 1984; Powers et al., 1983).

\section{Ratings of Perceived Exertion (RPE)}

Of the methods used to describe and quantify the physiological stress experienced during exercise, ratings of perceived exertion have received much attention. The 15-point Borg scale has been used to evaluate work intensity for exercise prescription. The scale uses values from 6 to 20 to approximate one-tenth of heart rate (HR) with verbal expressions corresponding to different levels of the scale and has been recommended by Borg (1982) as the best one for exercise testing, and for predictions and prescriptions of exercise intensities in sports and medical rehabilitation. Perceived exertion, a subjective perception of the overall effects of exercise, was described by Borg as:

The overall perceived exertion rating integrates various information, including the many signals elicited from the peripheral working muscles and joints, from the central 
cardiovascular and respiratory functions, and from the central nervous system. All these signals, perceptions, and experiences are integrated into a configuration or "Gestalt" of perceived exertion. (p. 377)

Ekblom and Goldbarg (1971) suggested that local factors, relating to strain in muscles and/or joints, act as primary cues in the perception of effort, and central factors, relating to sensations from the cardiopulmonary system, play more of a secondary role. Carton and Rhodes (1985) conclude from their review of several studies that physical strain in the working muscles appears to be the primary stimulus for effort perception during low levels of activity, with central inputs contributing to effort perception at higher workloads, such as at ventilatory threshold.

Skinner, Hustler, Bergsteinova and Buskirk (1973) found ratings of perceived exertion using the Borg scale to be linearly related to relative metabolic stress. The relative contribution of the local and central factors to the exertional ratings have been studied extensively, but with some contrasting findings (Pandolf, 1982). In 1977, Cafarelli suggested that local factors provided the primary sensory signals, their components depending upon the force and rate of muscular contractions, while central factors acted more like a gain modifier in proportion to the aerobic demand. Robertson (1982) reviewed the control factor input by HR, ventilation ( $\dot{V} E)$, and relative $\dot{V} O 2$, and concluded that $\dot{V} E$ and the relative VO2 contribute to the overall sense of exertion. Stamford (1976) found $H R, \dot{V} E$, respiratory rate (RR), and $\dot{V} O 2$ among factors contributing to the 
ratings of perceived exertion. Noble, Metz, Pandolf, Bell, Cafarelli, and Sime (1973) found $\dot{V} E$ and RR to be the best predictors of RPE.

As previously discussed, training should be at an intensity corresponding to the individual's AT. This is in agreement with American College of Sport Medicine's recommendation for training intensity of 50 to $90 \%$ of VO2max for developing and maintaining cardiorespiratory fitness (1980). Purvis and Cureton (1981) studied the perceived exertion at AT for 30 physically active subjects. They found that individuals perceived the point of anaerobic threshold similarly and found mean ratings of $13.1+/-0.9$ and $14.2+/-0.9$ at anaerobic threshold for females and males respectively. In a study of young and middle aged runners, Small (1982) found mean RPE at AT to be $13.27+/-1.6$ and 13.47 $+/-1.5$, respectively. The intensity level at AT was, according to these findings, rated as "somewhat hard" to "hard", as the rating of 13 is described as "somewhat hard" and 15 as "hard." Burke (1979) found an RPE of 13 at 65 to $80 \%$ of $\dot{V} O 2 m a x$ and found this intensity prescription successful in improving aerobic power.

Various studies have attempted to assess the validity and reliability of RPE testing. Skinner et al., (1973) concluded that small variations in intensity could be detected even when presented in random order. In a study by Stamford (1976) of 14 sedentary females, RPE values proved to be reproducible $(r=.76)$ during intense and less severe exercise using a test retest procedure. Normal subjects are capable of consistently identifying differences in workload; however, Morgan (1973) pointed out that there are exceptions when subjects are depressed, neurotic, or 
anxious. Borg and Linderholm (1970) found both healthy subjects and patients able to reproduce work capacity based upon RPE, with retesting conducted 2 to 4 weeks after an initial test.

Brooks and Fahey (1984) observed the need of repeated laboratory tests as the athlete improves when using the ventilatory inflection point as a training guide for the athlete and coach. Because subjects seem to be able to rate the relative intensity of work as related to anaerobic or ventilatory threshold, the subject can maintain optimal training intensity with increased or decreased fitness level when using RPE.

Maximal aerobic power is over $90 \%$ determined by genetics, and improved performance after maximal oxygen uptake (V்2max) plateaus seems to rely on the increased ability to work at a high percentage of vo2max. The anaerobic threshold or ventilatory threshold refers to the point where a sudden increase in blood lactate levels and minute ventilation is observed. This transition from aerobic to anaerobic energy sources has been identified by the mean of ratings of perceived exertion (RPE). Training intensity at the level of anaerobic or ventilatory threshold has been recommended when developing and maintaining cardiorespiratory fitness. 
Chapter 3

Procedures

\section{Besearch Design}

Fifteen trained runners were tested on three different occasions to determine ventilatory threshold (VT) and their ability to reproduce ratings of perceived exertion (RPE) at ventilatory threshold in consecutive tests. The exercise stimulus presented by changes in speed and grade of treadmill was the independent variable. The dependent variables were maximal oxygen uptake (VO2max), VT, and RPE. All subjects completed all treatments and testing procedures were the same for each subject.

\section{Subjects}

All 15 subjects were male runners at intercollegiate or club levels in the San Jose area with at least two years of background of training. They all met the definition of "distance runner" established for this study. The age range of the runners was 18 to 28 years. Prior to the first test, all 
subjects completed an informed consent form which was approved by the SJSU Human Subject Review Committee (Appendix A), and a training questionnaire (Appendix B).

\section{Testing procedures}

Subjects were asked to refrain from vigorous exercise during the 24 hours before each test. They were also asked to prepare for the test as they would for races or hard workouts, and tests were rescheduled if the subjects, for any reason, thought they were not ready to perform. Oxygen consumption, minute ventilation, and heart rate were measured during all three treadmill tests. For the first test, the maximal test, a modified protocol designed for ventilatory threshold testing in San Jose State University's Exercise Physiology/Biomechanics Laboratory was used. Each test began with a 3 minute warmup with the treadmill speed at $3.5 \mathrm{mph}$ and $0 \%$ grade. The starting speed in the maximal test was 6 mph with $0 \%$ grade. The speed was increased by $0.5 \mathrm{mph}$ every minute up to $11.0 \mathrm{mph}$ for 10 of 15 runners. The other 5 runners were running at a RPE of 15 or less at $11.0 \mathrm{mph}$ and for them the speed was increased to $11.5 \mathrm{mph}$. At that point (maximum speed of $11.0 \mathrm{mph}$ or $11.5 \mathrm{mph}$ ) the grade was increased by $2 \%$ every minute while tha speed was maintained. This continued until the subject could no longer persevere and the test was terminated. The same protocol was used for the second test, the first submaximai test, with the test terminating when subjects achieved the workload that corresponded to ventilatory threshold calculated from 
the maximal test data. In the third test, the second submaximal test, a test protocol specially designed for the purpose of this study was used. This test consisted of four interval workbouts of 90 seconds duration, with two minute active recovery at the beginning of the test and between work intervals. With $X=$ speed at which VT was reached in the maximal test, the speed of the treadmill in the four work intervals was $X-1 \mathrm{mph}$, $X-0.5 \mathrm{mph}, X$, and $X+0.5 \mathrm{mph}$. The order of the different intensities for the workbouts was randomly assigned for the subjects.

The maximal values for VंO2max measured in test one represented the subjects' true VO2max. The criteria used to determine VंO2max were a plateau in oxygen consumption, RER value of greater than 1.0, and $H R$ near predicted HRmax (Fox \& Mathews, 1981).

Ventilatory threshold was determined using gas exchange data. Gas exchange variables have been used by several researchers to detect anaerobic threshold and have been found to correlate well with invasive methods in incremental tests (Caiozzo et al., 1982; Davis et al., 1979; Wasserman et al., 1973). Reliability for detection of AT by gas variables has been established with a test-retest correlation of 0.93 (Caiozzo et al., 1982) and 0.94 (Davis et al., 1979).

All tests were done in San Jose State University's Exercise Physiology/Biomechanics Laboratory during the spring term of the 1985 - 1986 academic year. Each subject performed all three tests within 19 days. The tests were performed on a motor driven treadmill with workloads adjusted by means of changing speed or inclination using the same equipment and protocols for each subject. 
Before the first test the subjects visited the laboratory to become familiar with the equipment, fill out the consent form and questionnaire, and perform a practice run on the treadmill. The same protocol was used for the practice run as for the maximal test, except for the duration of each stage and lower maximal speed. Speed was increased every 30 to 40 seconds up to the speed of $10.5 \mathrm{mph}$. Subjects practiced pointing to the Borg scale (Appendix C) while running on the treadmill. Directions for using the Borg scale (Appendix D), were read by the subjects before the practice run. Hand signals to be used to communicate with the subjects during the tests were explained and practiced.

\section{Measurement of Physiological Variables}

Heart rate was recorded during the last 10 seconds of each minute using the Quinton EKG Monitoring System Model 623A and modified six lead configuration. Oxygen consumption was monitored throughout each test and gas variables were measured every 30 seconds to obtain sufficient data points to detect the threshold point as explained by Hughson (1984); "In conducting treadmill tests to determine the ventilatory threshold, care must be taken to obtain an adequate number of data points below the threshold to define the point of ventilation increase" (p.306). A mouthpiece on a Collins two-way respiratory valve was adjusted on each subject. Samples of expired air were drawn from a 4-liter mixing chamber into a Wilmore-Costill Semiautomatic Apparatus which includes three aliquot bags. Air from the aliquot bags was 
analyzed for percent $\mathrm{CO} 2$ and $\mathrm{O} 2$ by the Beckman LB-2 Medical Gas $\mathrm{CO} 2$ Analyzer and Applied Electrochemistry $\mathrm{O} 2$ Analyzer. The gas analyzers were calibrated immediately before each test, using a gas of known concentrations of carbon dioxide and oxygen. A Parkinson Cowan CD-4 Dry Gas Meter interfaced with a Gilson recorder was used to measure inspired gas volume. Environmental data were obtained to determine STPD and BTPS factors. The subjects' body weight measurement was taken prior to each test on an Accu Weigh balance-type scale. Skinfold measurements were taken to estimate percentage body fat using a Harpenden caliper. The skinfold sites measured were chest, abdomen, and thigh (Lamb, 1984).

To determine the VT a computer program "ATREG ANAEROBIC THRESHOLD BY LINEAR LEAST SQUARES", written by W. K. Prusaczyk, was used. Data were also plotted on a graph to check the program.

\section{Data Analysis}

Ventilatory threshold, derived from the gas exchange variables, and the $\dot{V} O 2 m a x$ were recorded for each subject. $\dot{V} O 2$ at VT was given as percentage of $\dot{V} O 2 m a x$ as well as in absolute values.

Three one way ANOVA's were used to determine if there was a significant difference in the RPE, VO2, and HR at VT between the three tests with the 0.01 alpha level being maintained for all analyses. Applying ANOVA three times for the three different variables precluded the use of the often used 0.05 alpha level of significance (SPSSX Advanced Statistics Guide, 1985). 


\section{Chapter 4}

Results and Discussion

Information about the physical and training characteristics of the subjects was obtained. The results were compared to the results of studies with subjects with similar characteristics.

Physical characteristics of the subjects are presented in Table 1. The mean age of the 15 subjects was 22.9 years, ranging from 18 to 28 . Mean value for body fat was well below average and in agreement with data for well trained distance runners. In a study by Morgan and Pollock (1977) percentage body fat for one group of middle and long distance runners $(N=11)$ was 5.79 ; it was 6.81 for another group of college runners $(\mathrm{N}=8)$. The mean value of the subjects in this study is 5.4 , whereas the mean value for elite distance runners $(\mathrm{N}=20)$ found in a study by Pollock, Gettman, Jackson, Ayres, Ward, and Linnerud (1977) was 4.7. 
Table 1

Physical Characteristics of Subjects

\begin{tabular}{lccc}
\hline & $\begin{array}{c}\text { Age } \\
\text { (years) }\end{array}$ & $\begin{array}{c}\text { Weight } \\
(\mathrm{kg})\end{array}$ & $\begin{array}{c}\text { Body fat } \\
(\%)\end{array}$ \\
\hline Mean & 22.9 & 65.4 & 5.4 \\
S.D. & 2.76 & 6.16 & 1.22 \\
Range & 11 & 10.9 & 5.03 \\
low & 18 & 57.5 & 3.26 \\
high & 28 & 67.4 & 7.29 \\
\hline
\end{tabular}

All subjects had extensive training backgrounds and were competing at intercollegiate or club levels. Information on training status of the subjects is presented in Table 2.

Table 2

Training Characteristics

\begin{tabular}{|c|c|c|c|}
\hline & Years of training & workours per week & mileage per week \\
\hline Mean & 7.8 & 8.1 & 58.0 \\
\hline S.D. & 3.60 & 2.90 & 16.87 \\
\hline Range & 11 & 10 & 61 \\
\hline low & 3 & 4 & 30 \\
\hline high & 13 & 13 & 90 \\
\hline
\end{tabular}


The average number of workouts per week of 8.1 and average mileage per week of 58.0 helps to explain the high aerobic capacity for this group of runners. The relatively large range in training volume can be explained by the differences in individual training programs for events from 1,500 to 10,000 meters. Runners doing high mileage (over $100 \mathrm{~km} /$ week or approximately 60 miles/week) have been found to have superior running economy which can be reflected in inreased ability to work close to VंO2max (Scrimgeour, Noakes, Adams, Myburgh, 1986).

Physiological responses at $\dot{\mathrm{V}} 2 \mathrm{max}$ are presented in Table 3.

Table 3

Physiological Variables at Maximal Exercise

\begin{tabular}{lccccc}
\hline & $\begin{array}{c}\dot{\text { VO2max }} \\
(\mathrm{ml} / \mathrm{kg} / \mathrm{min})\end{array}$ & $\begin{array}{c}\dot{\text { VO2max }} \\
(1 / \mathrm{min})\end{array}$ & $\begin{array}{c}\text { HRmax } \\
(\mathrm{b} / \mathrm{min})\end{array}$ & $\begin{array}{c}\dot{\text { VEmax }} \\
(1 / \mathrm{min})\end{array}$ & RPEmax \\
\hline Mean & 65.72 & 4.27 & 187.53 & 142.83 & 19.2 \\
S.D. & 5.91 & 0.38 & 10.87 & 15.43 & 0.89 \\
Range & 21.6 & 1.05 & 48 & 41 & 4 \\
low & 55.6 & 3.76 & 170 & 123.6 & 17 \\
high & 76.2 & 4.81 & 217 & 164.6 & 20 \\
& & & & & \\
\hline
\end{tabular}

The mean oxygen uptake of $65.72 \mathrm{ml} / \mathrm{kg} / \mathrm{min}$ and $4.27 \mathrm{I} / \mathrm{min}$ reflects the high aerobic capacity of the subjects. The value of the normally active 20 year old male has been found to be 44 to $47 \mathrm{ml} / \mathrm{kg} / \mathrm{min}$ (Costill, 1986) whereas for college runners the value found by Morgan 
and Pollock (1977) was $68.91 \mathrm{ml} / \mathrm{kg} / \mathrm{min}$. The maximum heart rate is lower than the predicted HRmax, whicit could be expected with trained distance runners (Costill, 1986). The mean RPE of 19.2 suggests that subjects were performing at maximum and supports the $\dot{V} O 2 m a x$ determination.

Physiological variables at ventilatory threshold are presented in Table 4. The mean percentage of maximal oxygen uptake at VT is consistent with results from other studies (Rusko \& Rahkila, 1982; Small, 1982). Sinall found a value of $76.04 \%$ for distance runners with mean $\dot{\mathrm{V} O} 2 \mathrm{max}$ of $65.1 \mathrm{ml} / \mathrm{kg} / \mathrm{min}$ and Rusko and Rahkila a value of $80 \%$ for cross-country skiers with vंO2max value of $62.0 \mathrm{ml} / \mathrm{kg} / \mathrm{min}$. These values are considerably higher than the $51.7 \%$ found for subjects with $\dot{\text { VO}} 2 \mathrm{max}$ value of $50.7 \mathrm{ml} / \mathrm{kg} / \mathrm{min}$ in a study by McLellan and Skinner (1985).

The mean RPE at VT in the VंO2max test was 13.8. Purvis and Cureton (1981) found a mean RPE of 13.6 at anaerobic threshold $(N=30)$ which was similar to that of 14.0 in a study of untrained subjects by Dressendorfer et al. (1981). Small (1982) found a mean RPE of 13.47 at ventilatory threshold for trained runners. The level of ventilation and lactic acid are physiological factors associated with anaerobic threshold and sensation of effort during exercise (Pandolf, 1978).

The range for the ratings of perceived exertion at VT in the first test was 9 to 16 . Only one subject had a rating below 11 . The remaining 14 had ratings ranging from 11 to 16 . This is in agreement with the data from Purvis and Cureton (1981) who found a range of 11 to 
Table 4

Physiological Variables at Ventilatery Threshold (VT) During Three

Treadmill Tests

\begin{tabular}{|c|c|c|c|c|c|c|}
\hline Test & RPE & $\begin{array}{c}\dot{\mathrm{V} O 2} \\
(\mathrm{~m} / \mathrm{kg} / \mathrm{min})\end{array}$ & $\%$ VO $2 \max$ & $\begin{array}{c}\text { HR } \\
(b / \mathrm{min})\end{array}$ & $\begin{array}{c}\text { VE } \\
(1 / \min )\end{array}$ & RER \\
\hline
\end{tabular}

Maxtest

$\begin{array}{ccccccc}\text { Mean } & 13.8 & 53.49 & 81.3 & 168.3 & 85.85 & 0.95 \\ \text { S.D. } & 2.08 & 7.76 & 9.44 & 16.3 & 18.81 & 0.73 \\ \text { Range } & 8 & 25.6 & 29.9 & 65 & 66.6 & 0.25 \\ \text { low } & 9 & 37.48 & 65.1 & 127 & 49.5 & 0.83 \\ \text { high } & 16 & 63.08 & 95 & 192 & 116.1 & 1.08\end{array}$

Submax 1

$\begin{array}{ccrrrr}\text { Mean } & 13.0 & 51.78 & 159.5 & 79.71 & 0.93 \\ \text { S.D. } & 2.78 & 9.15 & 14.0 & 20.06 & 0.09 \\ \text { Range } & 11 & 29.43 & 55 & 63.4 & 0.29 \\ \text { low } & 8 & 36.33 & 120 & 47.1 & 0.79 \\ \text { high } & 18 & 65.76 & 175 & 110.5 & 1.08\end{array}$

Submax 2

$\begin{array}{ccrrrr}\text { Mean } & 11.2 & 54.51 & 158.5 & 77.41 & 0.90 \\ \text { S.D. } & 2.01 & 8.36 & 16.1 & 13.34 & 0.04 \\ \text { Range } & 7 & 26.26 & 68 & 41.3 & 0.17 \\ \text { low } & 8 & 39.11 & 121 & 54.3 & 0.83 \\ \text { high } & 14 & 65.37 & 189 & 95.6 & 1.00\end{array}$


16 , and Small (1982) who found a range of 10 to 15 for ratings of perceived exertion at anaerobic threshold. The range for the second test was almost the same, except for 2 subjects, one who had a high rating of 18 and another who had a low rating of 8 . For the third test the range was 8 to 14 with three subjects reporting a low rating of 8 . The individual variation can be explained with day to day variation in physical and psychological well-being (Morgan, 1973).

According to these findings the verbal description of "somewhat hard" (ratings of 13) to "hard" (ratings of 15) corrrespond to the ratings of perceived exertion at ventilatory threshold. This is in agreement with the results of Small (1982) and Purvis and Cureton (1981). Burke (1979) found an RPE of 13, equating work at 65 to $80 \%$ of vo2max for most individuals, a workload effective in improving aerobic power.

One-way analyses of variance were used to compare RPE, VंO2, and HR obtained on the three tests to determine if there was a significant difference between the conditions. Table 5 summarizes the analyses of variance for the three variables. There were no significant differences at the 0.01 level among the means for RPE in the three different tests. The null hypothesis was accepted. That individuals can perceive the point of anaerobic or ventilatory threshold was supported by the findings of Purvis and Cureton (1981) and Burke and Collins (1984). The assumption was made that workload and corresponding $\mathrm{V} O 2$ would stay the same in all three tests and there was no significant difference found between VO2 at VT for the three different tests. 
Table 5

Analysis of Variance Between Ratings of Perceived Exertion (RPE).

Oxygen Consumption (VO2) and Heart Rate (HR) at Ventilatory Threshold (VT) During Three Treadmill Tests

\begin{tabular}{|c|c|c|c|c|}
\hline & SS & DF & MS & $F$ \\
\hline \multicolumn{5}{|l|}{ RPE at VT } \\
\hline Between & 53.2 & 2 & 26.6 & 5.0 \\
\hline Within & 224.8 & 42 & 5.4 & \\
\hline Total & 278 & 44 & & \\
\hline \multicolumn{5}{|l|}{ VO2 at VT } \\
\hline Between & 57.3 & 2 & 28.7 & 4.0 \\
\hline Within & 29993.9 & 42 & 71.3 & \\
\hline Total & 3051.2 & 44 & & \\
\hline \multicolumn{5}{|l|}{$\mathrm{HR}$ at VT } \\
\hline Between & 865.2 & 2 & 432.6 & 1.8 \\
\hline Within & 10096.4 & 42 & 240.4 & \\
\hline Total & 10951.6 & 44 & & \\
\hline
\end{tabular}


The simplest method to monitor the stress of exercise is generally thought to be measurement of heart rate (Costill, 1986). The results from this study show RPE and HR to be consistent at VT for the three tests. These two variables might work well if used together as suggested by Burke (1979).

It should be emphasized that the use of HR and RPE is certainly not a "either/or" proposition. The use of RPE is cost free, quick, and adds substantial information in efforts to individualize an exercise program. In combination with HR, individual differences may be more easily overcome. (p.37)

The use of RPE in a coaching situation may be very helpful. How large a variability in exercise intensity description is acceptable has not been studied extensively. Some coaches might want to accept lower confidence levels than $95 \%$ for the difference between mean RPE (13.8) in the first incremental test and the mean RPE (11.2) in the interval test and decide that the $18.8 \%$ lower ratings for the interval work signifies that RPE is not suitable for intensity monitoring in interval work. The findings that RPE can be used to identify ventilatory threshold is in agreement with other studies (Burke, 1979; Purvis \& Cureton, 1981) and suggest that RPE can be used to prescribe exercise intensity equal to anaerobic or ventilatory threshold.

The subjects were shown to be well trained distance runners with high aerobic capacity. Physiological responses to maximal and submaximal work were similar to those found in other studies of trained distance runners. The results of this study suggest that runners 
can perceive the point of ventilatory threshold. This can be useful when evaluating training intensity. 


\section{Chapter 5}

Summary, Conclusions, and Recommendations

The purpose of this study was to determine if there were differences in the ratings of perceived exertion at ventilatory threshold in successive tests of trained middle and long distance male runners.

\section{Summary}

Fifteen well trained middle and long distance male runners volunteered to be subjects for this study. All subjects were tested on three different occasions on a motor driven treadmill to determine if they could reproduce the ratings of perceived exertion (RPE) at ventilatory threshold (VT). The first test was a maximal test to determine maximal oxygen uptake (VO2max) and ventilatory threshold. The second and third tests were submaximal tests; one was incremental and the other consisted of randomly selected intervals. Oxygen uptake and minute ventilation measurements were made every 30 seconds using standard open circuit calorimetry. Ventilatory threshold was determined by means of a computer program. Subjects rated the perceived exertion during the last 10 seconds of each workload; heart rate was recorded at 
the same time period. Three one-way ANOVAs were used to determine if there were significant differences between RPE, oxygen consumption, or heart rate at VT in the three tests, with the 0.01 alpha level being maintained for all analyses. There was no significant difference for any of the three variables at the 0.01 level. The tests failed to reject the null hypothesis of the study that there would be no significant difference among the means for the subject's RPE at VT in three test protocols.

\section{Conclusions}

Trained middle and long distance runners can reproduce ratings of perceived exertion at ventilatory threshold for identical workload and oxygen consumption on different days. The data suggest that ratings of perceived exertion might be useful in regulation of intensity for training; however, strong conclusion cannot be drawn from this single study.

\section{Recommendations}

According to the findings of this study the 15-point Borg scale could be used to describe and quantify the physiological stress experienced during the exercise of running. The recommended workload effective in improving aerobic power could be identified by the verbal describtion of "somewhat hard" (ratings of 13) to "hard" (ratings of 15) on the 15-point Borg scale.

The length of the workbout in the interval protocol was 90 seconds so 
that subjects stayed on each workload for similar time as in the incremental test. There is a considerable jump in speed from the recovery workload to the workbout and it is questionable if 90 seconds is enough time to adjust physiologically to the higher workload. To understand the effect of the ratio between workbout and recovery time a new test protocol has to be constructed. Using a interval protocol with longer interval workbouts would allow for better adjustment to the workload. This would also strengthen the application of results to actual training workouts where distance runners do interval workouts with longer workbouts than 90 seconds.

In this study all testing and ratings of perceived exertion were done in the laboratory. Conducting a study in which the subjects would monitor their running paces in training according to a prior laboratory test would allow for comparison of the intensity from the laboratory test to that in the field situation. The results from a test like that would give information on the application of VT tests not available from this study.

Only trained male runners were tested in this study. To study and compare untrained subjects and females would add to the information on perceived exertion. Of special interest would be to study the possible changes in RPE at various stages of the menstrual cycle.

To increase the number of subjects is one way to make the study more reliable. Recommendation for a further study could involve grouping runners into distance groups according to training or racing distances (e.g. middle distances, longer distances, ultra long distances) and compare these groups. 
References

American College of Sports Medicine. (1980). Guideline for graded exercise testing and exercise prescription. Philadelphia: Lea \& Febiger.

Borg, G. A. V. (1973). Perceived exertion: A note on "history" and methods. Medicine and Science in Sports, 5(2), 90 - 93.

Borg, G. A. V. (1982). Psychophysiological bases of perceived exertion. Medicine and Science in Sports and Exercise, 14(5), 377 - 381.

Borg, G. A. V., \& Linderholm, H. (1970). Exercise performance and perceived exertion in patients with coronary insufficiency, arterial hypertension and vasoregulatory asthenia. Acta Medica Scandinavica, 187, 17 - 26.

Burke, E. J. (1979). Individualized fitness program using perceived exertion for the prescription of healthy adults. Jeurnal of Physical Education and Recreation, 49, $35-37$.

Burke, E. J., \& Collins, M. L. (1984). Using perceived exertion for the prescription of exercise in healthy adults. In R. C. Cantu (Ed.), Clinical Sperts Medicine (pp. 93 - 105). Lexington: The Collamore Press.

Burke, E. J., \& Franks, J. B. (1975). Changes in VंO2max resulting from bicycle training at different intensities holding total mechanical work constant. Besearch Quarterly, 46, 31 - 37. 
Cafarelli, E. (1977). Peripheral and central inputs to the effort sense during cycling exercise. European Journal of Applied Physiology and Occupational Physiology, 37, 181 - 189.

Caiozzo, V. L., Davis, J. A., Ellis, J. F., Azus, J. L., Vandagriff, R., Prietto, C. A., \& McMaster, W. C. (1982). A comparison of gas exchange indeces used to detect the anaerobic threshold. Journal of Applied Physiology: Respiration. Environment and Exercise Physiology, 53(5), 1184 - 1189.

Carton, R. L., \& Rhodes, E. C. (1985). A critical review of the litterature on ratings scales for perceived exertion. Sport Medicine, 2, 198 - 222.

Costill, D. L., \& Fox, E. L. (1969). Energetics of marathon running. Medicine and Science in Sports, 1, 81 - 86.

Costill, D. L., Fink, W. J., \& Pollock, M. L. (1976). Muscle fiber composition and enzyme activities of elite distance runners. Medicine and Science in Sports, 8(2), $96-100$.

Costill, D. L. (1986). Inside running: Basics of sports physiology. Indianapolis: Benchmark Press, Inc.

Daniels, J. T., Yarbrough, R. A., \& Foster, C. (1978). Changes in VंO2max and Running Performance with Training. European Journal of Applied Physiology, 39, $249-254$.

Davies, C. T. M., \& Knibbs, A. V. (1971). The training stimulus. Internationale Zeitschrift Angewandte Physiologie Einschliesslich Arbeitsphysiologie, 29, $299-305$. 
Davis, J. A., Frank, M. H., Whipp, B.J., \& Wasserman, K. (1979). Anaerobic threshold alterations caused by endurance training in middle-aged men. Journal of Applied Physiology: Respiration. Environment and Exercise Physiology, 46(6), 1039 - 1046.

Dressendorfer, R. H., Smith, J. L., Merrill, J., Catlin, M. J., Carmichael, F., Goodfliesh, R., Borysk, L., Gordon, S., \& Timmis, G. C. (1981). Quantification of exercise responses at anaerobic threshold in healthy men: relation to prescribed training heart rates. Medicine and Science in Sports and Exercise, 13, 79.

Ekblom, B., \& Goldbarg, A. N. (1971). The influence of physical training and other factors on the subjective rating of perceived exertion. Acta Physiologica Scandinavica, 83, 399 - 406.

Fox, E. L., Bartels, R. L., Billings, C. E., Mathews, D. K., Bason, R., \& Webb, W. M. (1973). Intensity and distance of interval training programs and changes in aerobic power. Medicine and Science in Sports, 5, 18 - 22.

Fox, E. L., \& Mathews, D. K. (1981). The physiological basis of physical education and athletics (3rd ed.). Philadelphia: Saunders Publishing.

Graham, T. E. (1984). Mechanisms of blood lactate increase during exercise.

The Physiologist, 27(4), 299 - 303.

Hagberg, J. M., Coyle, E. F., Carroll, J. E., Miller, J. F., Martin, W. H, \& Brooke, M. H. (1982). Exercise hyperventilation in patients with McArdle's disease. Journal of Applied Physiology: Respiration. Environment and Exercise Physiology, 52(4), 991 - 994. 
Holloszy, J. O. (1973). Biochemical adaptations to exercise: Aerobic metabolism. In J. H. Wilmore (Ed.), Exercise and sport sciences reviews (Vol. 1). New York: Academic Press.

Hughes, E. F., Turner, S. C., \& Brooks, G. A. (1982). Effects of glycogen depletion and pedaling speed on "anaerobic threshold". Journal of Applied Physiology: Respiration. Environment and Exercise Physiology, 52(6), 1598 - 1607.

Hughson, R. L. (1984). Methodologies for measurement of the anaerobic threshold. The Physiologist, 27(4), $304-311$.

Ivy, J. L., Withers, R. T., VanHandel, P. J., Elger, D. H., \& Costill, D. L. (1980). Muscle respiratory capacity and fiber type as determinants of lactate threshold. Journal of Applied Physiologx: Respiration. Environment and Exercise Physiology 48(3), 523 - 527.

Karlsson, J., Nordsjo, L. O., \& Saltin, B. (1973). Muscle glycogen utilization during exercise after physical training. Acta Physiologica Scandinavica, 20, $210-217$.

Katch, V., Weltman. A., Sady, S., \& Freedson, P. (1978). Validity of the relative percent concept for equating training intensity. European Journal of Applied Physiology 39, 219 - 227.

Kinderman, W., Simon, G., \& Keul, J. (1979). The significance of the aerobic transition for the determination of work load intensities during endurance training. European Journal of Applied Physiology and Qccupational Physiology 42, 25 - 34.

Klissouras, V. (1971). Heritability of adaptive variation. Journal of Applied Physiology 31(3), 338 - 344. 
Lamb, D.R. (1984). Physiology of exercise: Responses \& adaptation (2nd ed.). New York: Macmillan.

LaFontaine, T. P., Londeref, R. R., \& Spath, W. K. (1981). The maximal steady state versus selected running events. Medicine and Science in Sports and Exercise, 13(3), $190-193$.

Maugham, R. J., \& Leiper, J. B. (1983). Aerobic capacitiy and fractional utilization of aerobic capacity in elite and non-elite female marathon runners. European Journal of Applied Physiology 52, 80 - 87.

McArdle, W. D., \& Magel, J. R. (1970). Physical work capacity and maximum oxygen uptake in treadmill and bicycle exercise. Medicine and Science in Sports 2(3), $118-123$.

McLellan, T. M., \& Skinner, J. S. (1985). Submaximal endurance performance related to the ventilatory thresholds. Canadian Journal of Applied Sport Sciences 10(2), 81 -87.

Morgan, W. P. (1973). Psychological factors influencing perceived exertion. Medicine and Science in Sports 5(2), $97-103$.

Morgan, W. P., \& Pollock, M. L. (1977). Psychological characterization of the elite distance runner. In P. Milvy (Ed.), Annals of the New York Academy of Sciences: Vol. 301. The Marathon: Physiological, medical_epidemiological and psychological studies. New York: The New York Annals of Sciences.

Noble, B. J., Metz, K. F., Pandolf, K. B., Bell, C. W., Cafarelli, E., \& Sime, W. E. (1973). Perceived exertion during walking and running - II. Medicine and Science in Sports 5(2), 116 - 120. 
Orr, G. W., Green, H. J., Hughson, R. L. , \& Bennett, G. W. (1982). A computer linear regression model to determine ventilatory anaerobic threshold. Journal of Applied Physiology: Respiration. Environment and Exercise Physiology, 52(5), $1349-1352$.

Pandolf, K. B. (1978). Influence of local and central factors in dominating rated perceived exertion during physical work. Perceptual and Motor Skills $46,683-698$.

Pandolf, K. B. (1982). Differentiated ratings of perceived exertion during physical exercise. Medicine and Science in Sports and Exercise 14(5), $397-405$.

Pollock, M.L., Gettman, L. R., Jackson, A., Ayres, J., Ward, A., Linnerud, A. C. (1977). Body composition of elite distance runners. In P. Milvy (Ed.), Annals of the New York Academy of Sciences: Vol. 301. The Maraton: Physiological, medical, epidemiological, and psychological studies. New York: The New York Annals of Science.

Powers, S. K., Dodd, S., Deadson, R., Byrd, R., \& McKnight, T. (1983). Ventilatory threshold, running economy and distance running performance of trained athletes. Besearch Quarterly for Exercise and Sport 54,(2), 179 - 182.

Powers, S. K., Dodd, S., \& Garner, R. (1984). Precision of ventilatory and gas exchange alterations as a predictor of the anaerobic threshold. European Journal of Applied Physiology and Occupational Physiology 52, $173-177$.

Purvis, J. W., \& Cureton, K. J. (1981). Ratings of perceived exertion at anaerobic threshold. Ergonemics 24(4), 295 - 300. 
Robertson, R. J. (1982). Central signals of perceived exertion during dynamic exercise. Medicine and Science in Sports and Exercise 14(5), $390-396$.

Rusko, H., \& Rahkila, P. (1982). Maximum oxygen uptake, anaerobic threshold, and skeletal muscle enzymes in male athletes. In P. V. Komi (Ed.), Exercise and Sport Biology (pp. 68 - 75). Illinois: Human Kinetics Publishers.

Sady, S., Katch, V., Freedson, P., \& Weltman, A. (1980). Changes in metabolic acidosis; evidence for an intensity threshold. Journal of Sports Medicine and Physical Fitness, 20, 41 - 46.

Saltin, B., \& Åstrand, P. O. (1967). Maximal oxygen uptake in athletes. Journal of Applied Physiology, 23, 253 - 258.

Scrimgeour, A. G., Noakes, T. D., Adams, B., \& Myburgh, K. (1986). The influence of weekly training distance on fractional utilization of maximum aerobic capacity in marathon and utramarathon runners. European Journal of Applied Phsyiology and Occupational Physiology 55, $202-209$.

Sjodin, B., \& Svedenhag, J. (1985). Applied physiology of marathon running. Sports Medicine 2, 83 - 99.

Skinner, J. S., Hustler, R., Bergsteinova, V., \& Buskirk, E. R. (1973). The validity and reliability of rating scale of perceived exertion. Medicine and Science in Sports, 51(1), 234 - 247. SPSSX advanced statistics guide (1985). McGraw-Hill. 
Skinner, J. S., \& McLellan, T. H. (1980). The transition from aerobic to anaerobic metabolism. Research Quarterly for Exercise and Sport. 51(1), $234-247$.

Small, R. B. (1982). BPE AT in young and middle-aged male distance runners. Master's thesis, Springfield College, Massachusetts.

Smutok, M. A., Skrinar, G. S., \& Pandolf, G. B. (1980). Exercise intensity: Subjective regulation by perceived exertion. Archives of Physical Medicine and Rehabilitation 61, 569 - 574.

Stamford, B. A. (1976). Validity and reliability of subjective ratings of perceived exertion during work. Ergonomics 19(1), 53 - 60.

Tanaka, K., Matsuura, Y., Kumagai, S., Matsuzaka, A., Hirakoba, K., \& Asana, K. (1983). Relationship of anaerobic threshold and onset of blood lactate accumulation with endurance performance. European Journal of Applied Physilogx, 52, 51 - 56.

Wasserman, K., \& Mcllroy, M. B. (1964). Detecting the threshold of anaerobic metabolism. American Journal of Cardiology 14, 844 - 852.

Wasserman, K., Whipp, B. J., Koyal, S. N., \& Beaver, W. L. (1973). Anaerobic threshold and respiratory gas exchange during exercise. Journal of Applied Physiology 35(2), 236 - 243.

Weltman, A., \& Katch, V. (1979). Relationship between the onset of metabolic acidosis (anaerobic threshold) and maximal oxygen uptake. Journal of Sports Medicine 19, 135 - 141.

Weltman, A., Katch, V., Sady., \& Freedson, P. (1978). Onset of metabolic acidosis (anaerobic threshold) as a criterion measure of submaximal fitness. The Research Quarterly, 49(2), 219 - 227. 
Wilmore, J. H. (1977). Athletic training and physical fitness: physiological principles and practices of the conditioning process. Boston: Allyn and Bacon, Inc. 
Appendix A

Informed Consent 


\section{INFORMED CONSENT}

Consent to participate in physiological assessment project

NAME: DATE

\section{Procedures}

I herby authorize Gunnar Pall Joakimsson and his designated assistants to perform on me the following procedures: a) resting electrocardiographic (ECG) recording, b) maximal and submaximal exercise tests, c) skinfold measurements.

During the first visit to the laboratory, body composition measurements and a maximum exercise test will be made. The test will begin with a 3-min warm-up consisting of walking at a brisk pace. After the warm-up, the speed and/or the slope of the treadmill will be increased at the end of each minute of the test. The test will be terminated when sign of excessive fatigue or distress are observed, ECG wave form recordings show unusual changes, and/or the subject indicates a desire to stop because of feelings of fatigue, discomfort or distress. During all exercise testing the subject will be connected with ECG leads and heart rate and wave form will be monitored continuously. He will breath through a mouthpeace with a noseclip in place. At specific times, the subject will be asked to subjectively rate the exercise intensity on a numerical scale. Skinfold will be measured with Harpenden calipers.

The tests on visits two and three to the laboratory will be submaximal tests, but performed in a similar way as test one.

The above procedures were verbally explained to me by:

(initial here)

2. Discomforts and Risks

Discomforts associated with the above procedures include breathing through a mouthpeace with nose clip in place, the mild pain associated with the pinch used to take skinfold measurements and discomfort commonly associated with exercise: sweating, increaseing heart rate, breathing rate, and body temperature, and fatigue. 
Graded Exercise Test.

Changes that may be anticipated at or near maximal exertion include abnormal blood pressue, fainting, dizziness, muscle fatigue or cramps, nausea, and abnormal heart beat. individuals will be excluded from participation in this investigation when abnormalities are detected in pulmonary function or electrocardiographic recordings.

Skinfold measurements.

Although seldom occuring, bruises may result from skinfold measurements.

I understand that the procedures described above involve some risk and that exercise changes may present discomfort.

4. Inquires. (initial here)

The investigator and his assistants will answer any questions pertaining to the testing procedures. Please feel free to ask for further explainations if you have any doubts or questions.

5. Withdrawal of Consent.

Participation in this study is voluntary.

I understand that I may withdraw my consent and discontinue participation in the project any time wothout prejudice. I further understand that if during any of the exercise sesseions I feel I can no longer continue to exercise, regardless of the reason, I am free to terminate that session. I also understand that I am free to decline to answer any specific item or question on any questionnaires.

(initial here)

6. Confidentiality.

I agree that the data generated from these experiments may by used for medical and scientific purpose, including publication and presentation at professional meetings, with the understanding that my identity will not be revealed unless expressly consented thereto.

(initial here) 
I have read this form and have had the procedures explained to me. I understand the exercise and other testing procedures and freely consent to participate in this study.

Date

Date
Signature

Witness signature 
Appendix B

Questionnaire 


\section{Questionnaire}

You are invited to take part in a study that looks at trained runners, and is a part of a master's thesis in exercise physiology.

Each subject needs to come to the laboratory four times, once for a max test, twice for submax tests, and once for a practice session. Each test consists of running on a motor driven treadmill. Subjects breathe through a mouthpeace so calculations can be made for oxygen consumption. Heart rate will be constantly measured by means of EKG (electrocardiogram). Subjects will be asked to estimate how they feel at different workloads. No invasive measurements will be made.

All results from the tests, which include information on maximal oxygen uptake, the power of the aerobic system, will be sent to each athlete participating in the study.

Please fill out this form before testing will be sceduled. Name:

Address:

Telephone: Best time to call:

Born:

Number of years trained for competition:

Events trained for and best times:

Number of workouts per week (average):

Mileage run per week (Average):

How do you decide intensity or pace for your distance runs?

a. by a stopwatch and/or mile marks

b. pulse rate

c. general feeling

d. other 
What time of day are you available for testing?

Mon

Wed

Fri

Tue

Thu

Sat

Sun 
Appendix C

Borg's RPE Scale 
Borg's scale for ratings of perceived exertion

6

7 Very, very light

8

9 Very light

10

11 Fairly light

12

13 Somewhat hard

14

15 Hard

16

17 Very hard

18

19 Very, very hard

20 
Appendix D

Directions for Use of Borg's RPE Scale 


\section{RATING OF SUBJECTIVE FEELINGS OF WORK EFFORT}

You are now going to take part in a work test. You will be running on the treadmill while we are measuring various physiological functions. The speed at which you run will be gradually increased until you are running at your "race pace"; then the slope will be increased until you reach exhaustion. While we are taking the physiological measurements, we want you to try to estimate how hard you feel the work is; that is, we want you to rate the degree of perceived exertion you feel. By perceived exertion we mean the total amount of exertion and physical fatigue, combining all sensations and feelings of physical stress, effort, and fatigue. Don't concern yourself with any one factor such as leg pain, shortness of breath, or the work intensity, but try to concentrate on your total, inner feeling of exertion. Try to estimate as honestly and objectively as possible. Don't underestimate the degree of exertion you feel, but don't overestimate it either. Just try to estimate as accurately as possible.

You may use any number on the scale. A rating of 19 (very, very strong) should be associated with the heaviest or most stressful exercise ever performed; however, it is possible to perceive effort that is even more stressful than 19.

Keep in mind that there are no right or wrong answers. Use any number you think is appropriate. Do not be swayed by what others report; different individuals will have different feelings for the same work load. You will be asked for your rating during the last few seconds of each 
work load. INDICATE your rating BY PLACING A FINGER OVER THE NUMBER THAT BEST REPRESENTS YOUR PERCEIVED EXERTION.

If you do not understand these instructions or have further questions, please feel free to ask one of the researchers. 
Appendix $E$

Individual Data at Maximal Exercise and for \% Body Fat and Weight 
Individual Data at Maximal Exercise and for \% Body Fat and Weight

\begin{tabular}{|c|c|c|c|c|c|}
\hline Subject & $\begin{array}{l}\dot{\mathrm{V} O} 2 \mathrm{max} \\
(\mathrm{ml} / \mathrm{kg} / \mathrm{min})\end{array}$ & $\begin{array}{c}\dot{\text { VOO2max }} \\
\text { (1/min) }\end{array}$ & $\begin{array}{l}\text { HRmax } \\
(b / \text { min) }\end{array}$ & $\begin{array}{r}\dot{V} E \max \\
(1 / \min )\end{array}$ & RPEmax \\
\hline 1 & 68.4 & 4.21 & 189 & 154.8 & 20 \\
\hline 2 & 62.1 & 4.58 & 184 & 160.4 & 20 \\
\hline 3 & 59.6 & 4.02 & 170 & 123.6 & 18 \\
\hline 4 & 72.2 & 4.33 & 184 & 150.1 & 19 \\
\hline 5 & 61.2 & 4.11 & 176 & 153.9 & 19 \\
\hline 6 & 69.7 & 4.41 & 178 & 138.7 & 19 \\
\hline 7 & 69.3 & 4.02 & 186 & 142.6 & 19 \\
\hline 8 & 55.6 & 3.76 & 193 & 151.7 & 20 \\
\hline 9 & 76.2 & 4.46 & 186 & 133.4 & 18 \\
\hline 10 & 59.5 & 3.49 & 192 & 130.0 & 20 \\
\hline 11 & 66.2 & 4.76 & $i 86$ & 133.4 & 20 \\
\hline 12 & 74.0 & 4.27 & 188 & 131.6 & 17 \\
\hline 13 & 63.0 & 4.81 & 200 & 152.4 & 20 \\
\hline 14 & 66.5 & 4.80 & 184 & 164.6 & 20 \\
\hline 15 & 62.3 & 4.01 & 217 & 145.4 & 19 \\
\hline
\end{tabular}


Individual Data at Maximal Exercise and for \% Body Fat \& Weight (continued)

\begin{tabular}{|c|c|c|c|c|}
\hline Subject & VT(ن்O2) & VT(\%ं் & $\%$ Body fat & $\begin{array}{c}\text { weight } \\
(\mathrm{kg})\end{array}$ \\
\hline 1 & 62.0 & 90.6 & 3.26 & 61.6 \\
\hline 2 & 55.8 & 89.9 & 5.17 & 73.8 \\
\hline 3 & 37.5 & 62.9 & 4.73 & 67.5 \\
\hline 4 & 58.8 & 80.6 & 5.21 & 60.0 \\
\hline 5 & 54.6 & 89.2 & 5.34 & 67.2 \\
\hline 6 & 62.4 & 89.5 & 5.39 & 63.5 \\
\hline 7 & 51.9 & 74.9 & 6.96 & 58.2 \\
\hline 8 & 52.8 & 95 & 7.29 & 67.6 \\
\hline 9 & 60.9 & 79.9 & 4.81 & 58.5 \\
\hline 10 & 47.7 & 80.2 & 6.80 & 59.8 \\
\hline 11 & 47.7 & 71.9 & 6.02 & 71.9 \\
\hline 12 & 63.1 & 85.2 & 3.51 & 57.7 \\
\hline 13 & 41.0 & 65.1 & 5.10 & 76.4 \\
\hline 14 & 56.8 & 85.4 & 4.71 & 72.2 \\
\hline 15 & 49.4 & 79.3 & 7.09 & 64.4 \\
\hline
\end{tabular}


Appendix F

Individual Data for Physiological Variables at Ventilatory Threshold 


\section{Physiological Variables at Ventilatory Threshold}

\begin{tabular}{|c|c|c|c|c|c|c|c|}
\hline Subject & test & RPE & $\begin{array}{c}\dot{\mathrm{V} O 2} \\
(\mathrm{~m} / \mathrm{kg} / \mathrm{min})\end{array}$ & $\%$ VOO $2 \max$ & $\begin{array}{c}\text { HR } \\
\text { (b/min) }\end{array}$ & $\begin{array}{l}\dot{V} E \\
(1 / \mathrm{min})\end{array}$ & $R$ \\
\hline 1 & $\begin{array}{l}\text { Maxtest } \\
\text { Submax } 1 \\
\text { Submax } 2\end{array}$ & $\begin{array}{l}11 \\
12 \\
13\end{array}$ & $\begin{array}{l}47.71 \\
46.45 \\
45.62\end{array}$ & 71.9 & $\begin{array}{l}152 \\
150 \\
146\end{array}$ & $\begin{array}{l}65 \\
64.6 \\
64.4\end{array}$ & $\begin{array}{l}.86 \\
.85 \\
.91\end{array}$ \\
\hline 2 & $\begin{array}{l}\text { Maxtest } \\
\text { Submax } 1 \\
\text { Submax } 2\end{array}$ & $\begin{array}{l}15 \\
15 \\
12\end{array}$ & $\begin{array}{l}58.83 \\
55.50 \\
62.83\end{array}$ & 80.6 & $\begin{array}{l}160 \\
157 \\
150\end{array}$ & $\begin{array}{l}85.3 \\
76.6 \\
91.8\end{array}$ & $\begin{array}{l}.88 \\
.88 \\
.85\end{array}$ \\
\hline 3 & $\begin{array}{l}\text { Maxtest } \\
\text { Submax } 1 \\
\text { Submax } 2\end{array}$ & $\begin{array}{l}15 \\
15 \\
10\end{array}$ & $\begin{array}{l}55.83 \\
58.81 \\
54.34\end{array}$ & 89.9 & $\begin{array}{l}168 \\
168 \\
171\end{array}$ & $\begin{array}{r}102.2 \\
108.5 \\
91.2\end{array}$ & $\begin{array}{r}1.05 \\
1.08 \\
.92\end{array}$ \\
\hline 4 & $\begin{array}{l}\text { Maxtest } \\
\text { Submax } 1 \\
\text { Submax } 3\end{array}$ & $\begin{array}{l}16 \\
15 \\
13\end{array}$ & $\begin{array}{l}62.01 \\
62.66 \\
65.37\end{array}$ & 90.6 & $\begin{array}{l}182 \\
164 \\
162\end{array}$ & $\begin{array}{r}116.1 \\
110.5 \\
88.2\end{array}$ & $\begin{array}{r}1.03 \\
1.02 \\
.92\end{array}$ \\
\hline 5 & $\begin{array}{l}\text { Maxtest } \\
\text { Submax } 1 \\
\text { Submax } 2\end{array}$ & $\begin{array}{l}9 \\
9 \\
8\end{array}$ & $\begin{array}{l}37.48 \\
36.44 \\
39.11\end{array}$ & 69.9 & $\begin{array}{l}127 \\
120 \\
121\end{array}$ & $\begin{array}{l}49.5 \\
47.1 \\
54.3\end{array}$ & $\begin{array}{l}.84 \\
.86 \\
.91\end{array}$ \\
\hline 6 & $\begin{array}{l}\text { Maxtest } \\
\text { Submax } 1 \\
\text { Submax } 2\end{array}$ & $\begin{array}{l}13 \\
10 \\
13\end{array}$ & $\begin{array}{l}54.61 \\
53.72 \\
57.01\end{array}$ & 89.2 & $\begin{array}{l}158 \\
154 \\
152\end{array}$ & $\begin{array}{r}107.8 \\
72.0 \\
87.3\end{array}$ & $\begin{array}{l}.92 \\
.79 \\
.83\end{array}$ \\
\hline 7 & $\begin{array}{l}\text { Maxtest } \\
\text { Submax } 1 \\
\text { Submax } 2\end{array}$ & $\begin{array}{l}16 \\
16 \\
12\end{array}$ & $\begin{array}{l}62.40 \\
65.76 \\
62.50\end{array}$ & 89.5 & $\begin{array}{l}170 \\
166 \\
158\end{array}$ & $\begin{array}{l}96.5 \\
96.7 \\
85.9\end{array}$ & $\begin{array}{l}.98 \\
.99 \\
.88\end{array}$ \\
\hline 8 & $\begin{array}{l}\text { Maxtest } \\
\text { Submax } 1 \\
\text { Submax } 2\end{array}$ & $\begin{array}{l}15 \\
14 \\
13\end{array}$ & $\begin{array}{l}51.90 \\
50.34 \\
50.17\end{array}$ & 74.9 & $\begin{array}{l}164 \\
161 \\
156\end{array}$ & $\begin{array}{l}70.3 \\
62.3 \\
59.2\end{array}$ & $\begin{array}{l}.94 \\
.95 \\
.90\end{array}$ \\
\hline 9 & $\begin{array}{l}\text { Maxtest } \\
\text { Submax } 1 \\
\text { Submax } 2\end{array}$ & $\begin{array}{l}15 \\
13 \\
10\end{array}$ & $\begin{array}{l}52.81 \\
50.59 \\
56.1\end{array}$ & 95.0 & $\begin{array}{l}181 \\
175 \\
176\end{array}$ & $\begin{array}{r}109.7 \\
103.0 \\
87.3\end{array}$ & $\begin{array}{r}1.08 \\
1.06 \\
.93\end{array}$ \\
\hline 10 & $\begin{array}{l}\text { Maxtest } \\
\text { Submax } 1 \\
\text { Submax } 2\end{array}$ & $\begin{array}{l}16 \\
18 \\
14\end{array}$ & $\begin{array}{l}60.85 \\
60.17 \\
61.37\end{array}$ & 79.9 & $\begin{array}{l}169 \\
169 \\
171\end{array}$ & $\begin{array}{l}89.9 \\
92.4 \\
95.6\end{array}$ & $\begin{array}{r}.92 \\
.96 \\
1.00\end{array}$ \\
\hline
\end{tabular}


Physiological Variables at Ventilatory Threshold (continued)

\begin{tabular}{|c|c|c|c|c|c|c|c|}
\hline Subject & test & RPE & $\begin{array}{c}\dot{\mathrm{VO} 2} \\
(\mathrm{ml} / \mathrm{kg} / \mathrm{min})\end{array}$ & $\% \dot{V O} 2 \max$ & $\begin{array}{l}\mathrm{HR} \\
(\mathrm{b} / \mathrm{min})\end{array}$ & $\begin{array}{c}\dot{\mathrm{V} E} \\
(\mathrm{l} / \mathrm{min})\end{array}$ & R \\
\hline 11 & $\begin{array}{l}\text { Maxtest } \\
\text { Submax } 1 \\
\text { Submax } 2\end{array}$ & $\begin{array}{l}14 \\
14 \\
12\end{array}$ & $\begin{array}{l}47.70 \\
57.75 \\
54.51 .\end{array}$ & 80.2 & $\begin{array}{l}192 \\
167 \\
162\end{array}$ & $\begin{array}{l}74.1 \\
78.3 \\
73.1\end{array}$ & $\begin{array}{l}.99 \\
.81 \\
.90\end{array}$ \\
\hline 12 & $\begin{array}{l}\text { Maxtest } \\
\text { Submax } 1 \\
\text { Submax } 2\end{array}$ & $\begin{array}{l}14 \\
13 \\
11\end{array}$ & $\begin{array}{l}63.08 \\
40.97 \\
60.35\end{array}$ & 85.2 & $\begin{array}{l}176 \\
169 \\
162\end{array}$ & $\begin{array}{l}79.4 \\
72.1 \\
65.6\end{array}$ & $\begin{array}{l}.91 \\
.94 \\
.88\end{array}$ \\
\hline 13 & $\begin{array}{l}\text { Maxtest } \\
\text { Submax } 1 \\
\text { Submax } 2\end{array}$ & $\begin{array}{l}13 \\
10 \\
11\end{array}$ & $\begin{array}{l}40.97 \\
36.33 \\
39.45\end{array}$ & 65.1 & $\begin{array}{l}161 \\
144 \\
140\end{array}$ & $\begin{array}{l}68.7 \\
57.1 \\
66.5\end{array}$ & $\begin{array}{l}.87 \\
.84 \\
.91\end{array}$ \\
\hline 14 & $\begin{array}{l}\text { Maxtest } \\
\text { Submax } 1 \\
\text { Submax } 2\end{array}$ & $\begin{array}{r}14 \\
13 \\
8\end{array}$ & $\begin{array}{l}56.79 \\
56.03 \\
60.64\end{array}$ & 85.4 & $\begin{array}{l}173 \\
173 \\
162\end{array}$ & $\begin{array}{l}94.3 \\
94.8 \\
80.8\end{array}$ & $\begin{array}{r}1.01 \\
1.02 \\
.87\end{array}$ \\
\hline 15 & $\begin{array}{l}\text { Maxtest } \\
\text { Submax } 1 \\
\text { Submax } 2\end{array}$ & $\begin{array}{r}11 \\
8 \\
8\end{array}$ & $\begin{array}{l}49.83 \\
45.12 \\
48.30\end{array}$ & 79.3 & $\begin{array}{l}191 \\
155 \\
189\end{array}$ & $\begin{array}{l}79.0 \\
59.6 \\
70.0\end{array}$ & $\begin{array}{l}.94 \\
.89 \\
.94\end{array}$ \\
\hline
\end{tabular}


Appendix G

\section{Publication manuscript}


Reproducibility and application of perceived exertion at ventilatory threshold for trained runners.

Gunnar Pall Joakimsson

San Jose State University

\section{Abstract}

JOAKIMSSON, G. P. Reproducibility of perceived exertion at ventilatory threshold for trained runners. Acta Physiologica Scandinavica. The purpose of this study was to determine the ability to reproduce ratings of perceived exertion (RPE) at ventilatory threshold (VT). Fifteen well trained middle and long distance male runners (mean VंO2max 65.7 $\mathrm{ml} / \mathrm{kg} / \mathrm{min}$ ), aged 18 to 28 , were tested on three different occasions. Maximal oxygen uptake (VัO2max) and VT were determined in a graded exercise test. The workload corresponding to ventilatory threshold in the maximal test was repeated in one incremental submaximal test and one interval submaximal test. Subjects indicated their RPE during the last 10 seconds of each workload using the 15 point Borg scale. The mean values for RPE were $13.8+/-2.1,13.0+/-2.8$, and $11.2+/-2.0$ for the three tests. One-way ANOVA's revealed no significant difference between RPE or VO2 at VT for the three tests at the 0.01 level of significance. These results suggest that trained runners can use ratings of perceived exertion to regulate training intensity at ventilatory threshold. 
Gunnar Pall Joakimsson

Managata 24, 105 Reykjvaik, ICELAND

The ablility to consume oxygen and utilize energy is of fundamental importance in all endurance events. The high maximal oxygen uptake (VO2max) of distance runners is well known (Saltin \& Åstrand, 1967). When studying the performance of well trained distance runners, the ability to work at a high percentage of one's VO2max seems to correlate even better with performance than v02max itself (Costill, Fink \& Pollock, 1976; Sjodin \& Svedenhag, 1985). This level at which submaximal work can be performed for a prolonged time can be measured as anaerobic threshold or ventilatory threshold (Weltman, Katch, Sady \& Freeuson, 1978). To increase the aerobic power and the ability to work at a high percentage of the VO2max, training intensities equal to or above the individual's AT are recommended (Burke \& Franks, 1975; Sady, Katch, Freedson \& Weltman, 1980). The purpose of this study was to obtain more knowledge about ratings of perceived exertion (RPE) as a technique for monitoring training intensity at anaerobic threshold.

Methods

Fifteen runners participated in this study. Each had at least two years background of training. Their age range was 18 to 28 years. Each subject performed three tests within the time span of 19 days. Prior to the first test all subjects visited the laboratory for a practice run on the 


\section{PLEASE NOTE:}

Page(s) not included with original material and unavailable from author or university. Filmed as received. 
Samples of expired air were drawn into the Willmore-Costill Semiautomatic Apparatus and then analyzed for percent $\mathrm{CO} 2$ and $\mathrm{O} 2$ by the Beckman LB-2 Medical Gas CO2 Analyzer and Applied Electrochemistry O2 Analyzer. A Parkinson Cowan CD-4 Diy Gas Meter interfaced with a Gilson recorder was used to measure inspired gas volume. Ventilatory threshold was determined with a computer program, "ATREG ANAEROBIC THRESHOLD BY LINEAR LEAST SQUARES." Three one way ANOVA's were used to determine if there was a significant difference in the RPE, VO2, and HR at VT between the three tests with the 0.01 alpha level being maintained for all analysis.

Results and discussion

Physical and training charactaristics were obtained from all the fifteen runners. Their mean weight was $65.4 \mathrm{~kg}$ and mean body fat, as determined by skinfold measurements, was $5.4 \%$. The mean values for years of training, workouts per week and mileage per week were 7.8, 8.1, and 58.0, respectively. Physical variables at maximal exercise were as follows (mean values): $\dot{V} O 2 \max (\mathrm{ml} / \mathrm{kg} / \mathrm{min}) 65.72$, $\mathrm{V} O 2 \max (\mathrm{l} / \mathrm{min}) 4.27$, HRmax $(b / \min ) 187.5$, VEmax $(1 / \min ) 142.83$, and RPEmax 19.2. The mean percentage of maximal oxygen uptake at VT was $81.3 \%$. Mean values for RPE at VT were 13.8 in the max test, 13.0 in the first submax test and 11.2 for the third max test. This is in agreement with the results of other studies where mean values of RPE at VT were 13.47 to 14.0 (Dressendorfer et al., 1981; Purvis \& Cureton, 1981; Small, 1982). 
The verbal description of "somewhat hard" (ratings of 13) to "hard" (ratings of 15) correspond, according to these results, to the ratings of perceived exertion at ventilatory threshold.

There was no significant difference at the 0.01 level among the means for RPE in the three tests. There was no significant difference between VO2 at VT for the three different tests varifying the assumption made prior to testing that workload and corresponding $\dot{V} O 2$ would stay the same in all the three tests.

The result of this study show RPE and HR to be consistant at VT for the three tests. The finding that RPE can be used to identify ventilatory VT is in agreement with other studies (Burke, 1979; Purvis \& Cureton, 1981) and suggests that RPE can be used to prescribe exercise intensity equal to anaerobic threshold. 


\section{References}

Burke, E. J. (1979). Individualized fitness program using perceived exertion for the prescription of healthy adults. Journal of Physical Education and Recreation 49, 35 -37.

Burke, E. J., \& Franks, J. B. (1975). Changes in VंO2max resulting from bicycle training at different intensities holding total mechanical work constant. Besearch Quarterly, 46, 31 - 37.

Costill, D. L., Fink, W. J., \& Pollock, M. L. (1976). Muscle fiber composition and enzyme activities of elite distance runners. Medicine and Science in Sports 8(2), $96-100$.

Dressendorfer, R. H., Smith, J. L., Merrill, J., Catlin, M. J., Carmichael, F., Goodfliesh, R., Borysk, L., Gordon, S., \& Timmis, G. C. (1981). Quantification of exercise responses at anaerobic threshold in healthy men: relation to prescribed training heart rates. Medicine and Science in Sports and Exercise 13, 79.

Purvis, J. W., \& Cureton, K. J. (1981). Ratings of perceived exertion at anaerobic threshold. Ergonomics, 24(4), 295 - 300.

Sady, S., Katch, V., Freedson, P., \& Weltman, A. (1980). Changes in metabolic acidosis; evidence for an intensity threshold. Journal of Sperts Medicine and Physical Fitness 20, 41 - 46. 
Saltin, B., \& Åstrand, P. O. (1967). Maximal oxygen uptake in athletes. Journal of Appolied Physiology, 23, 253 - 258.

Sjodin, B., \& Svedenhag, J. (1985). Applied physiology of marathon running. Sports Medicine 2, 83 - 99.

Small, R. B. (1982). RPE AT in young and middle-aged male distance runners. Master's thesis, Springfield College, Massachusetts.

Weltman, A., Katch, V., Sady., \& Freedson, P. (1978). Onset of metabolic acidosis (anaerobic threshold) as a criterion measure of submaximal fitness. The Research Quarterly, 49(2), 219 - 227. 